\title{
Review \\ Noise Pollution and Control in Wood Mechanical Processing Wood Industries
}

\author{
Mayowa Jacob Owoyemi 1,*, Babajide Charles Falemara ${ }^{2}$ and Ayomide Joseph Owoyemi ${ }^{3}$ \\ 1 Forestry and Wood Technology, Federal University of Technology, Akure, Nigeria \\ 2 Forestry Technology Department, Federal College of Forestry, Jos, Plateau State, Nigeria; \\ fbabajide@gmail.com \\ 3 College of Medicine, University of Lagos, Lagos, Nigeria; jmowoyemi@futa.edu.ng \\ * Correspondence: jacobmayowa@yahoo.com
}

\begin{abstract}
High level of noise is a disturbance to the human environment. Noise in industries is also an occupational hazard because of its attendant effects on workers' health. Noise presents health and social problems in industrial operations, and the source is related to the machineries used in the industries. One of the unique features of the noise associated with wood machinery is the level of exposure and duration. Equipment used in a factory can be extremely loud. They can produce noise at decibels high enough to cause environmental health and safety concerns. The mechanically driven transport and handling equipment, cutting, milling, shaping and dust extractor installations in the wood industry generate noise. The sources of noise pollution have increased due to non-compliance with basic safety practices. The increased use of locally fabricated machine in the industry has increased the level of noise and vibration. The effects of industrial noise pollution as discussed include: increase in blood pressure; increased stress; fatigue; vertigo; headaches; sleep disturbance; annoyance; speech problems; dysgraphia, which means reading/learning impairment; aggression; anxiety and withdrawal. As presented in this paper, noise control techniques include; sound insulation, sound absorption, vibration damping and Vibration isolation.
\end{abstract}

Keywords: noise pollution; mechanical wood industries; equipment; control

\section{Introduction}

Economic wood processing is not possible without employing the use of machines for sawing, cutting, chipping and milling of timber. The major timber sub-sectors include: felling and transport; mechanical woodworking (sawing, shaping, milling, sanding); manufacture of wood board materials (plywood, chipboard and fiberboard); transformation into other products with extensive chemical modification of timber; and combustion [1].

Development of industry and technology and the use of industrial new techniques have apparently presented a comfortable life for human being, but with negative aspects that has caused workers to be exposed to numerous harmful effects. The environmental impacts of woodworking and wood processing operations, in the form of dust, noise and odours, have highly significant consequences. Noise pollution is one of the important issues of pollutant in work-places and is almost one of the harmful agents. The World Health organization (WHO) estimates that 250 million people have hearing loss and two third of these people are living in developing countries [2].

Industrial noise pollution poses a big challenge with every passing day and is a threat to safety and health of the people who are working in the industry and common people as well. It has been scientifically proven that noise more than 85 decibels can cause hearing impairment also accidents. Noise pollution sources may be too close to human habitats which prevent the noise from fading before it reaches human ear.

Industrial machinery and processes are composed of various noise sources such as rotors, stators, gears, fans, vibrating panels, turbulent fluid flow, impact processes, electrical machines, 
internal combustion engines etc. The mechanisms of noise generation depend on the particularly noisy operations and equipment including crushing, riveting, shake-out (foundries), punch presses, drop forges, drilling, lathes, pneumatic equipment (e.g. jack hammers, chipping hammers, etc.), machine tools such as lathes, milling machines and grinders, plant conveying systems and transport vehicles [3].

Noise is generated in all production activities, from primary processing to finishing. While people around an industrial facility and the people within it are both affected by industrial noise, it is the workers within the plant that generally bear the brunt of most of it [4]. The objective of this paper was to review and assess the impacts of noise pollution and control in mechanical processing wood industries

\section{Noise Emissions}

Noise is defined as unpleasant or unwanted sound released into the environment. It disturbs the human being causing adverse effects on the mental and psychological wellbeing. In other words it is simply the rapid fluctuation of air pressure, usually resulting from the vibration of a noise source. The rate of these fluctuations determines the pitch of the noise and their magnitude determines the volume. The human ear is not as responsive to low-frequency sound as it is to high-frequency sound. This effect can be simulated electronically and the resulting overall level is referred to as the Aweighted level or the $\mathrm{dB}(\mathrm{A})$ level [5]. The A-weighting is simply a way of adding up the noise intensity from all the sound frequencies (pitches) so as to reflect the actual hearing response of the human ear. For example, very low and very high frequencies are less hazardous than the middle frequencies. Different people may respond differently to the same level of noise. But above certain levels, noise can affect everybody. It can lead to hearing loss, mental stress and irritation. The industrial limit of sound in the industries must be $75 \mathrm{~dB}$ according to the World Health Organization [6].

Noises are generated by operational activities of a diversity of machine tools and equipment. Noise nuisance from wood processing is generated from circular saws, planers, routers and other equipment. In many countries, noise-induced hearing loss is one of the most prevalent occupational diseases. The industry provides a series of noise problems which are not always easily resolved, due to the different types of noise [7]. Noise levels generated by sawmill saws in operation vary from $80 \mathrm{~dB}$ up to $120 \mathrm{~dB}$. Moreover, not only can the cutting noise be extreme, there is also the additional factor that, even when idling, saws can produce noise levels up to $95 \mathrm{~dB}$.

The main sources of noise associated with the sawmill operation include: Transportation, unloading and loading of logs; Chain saw use for off-cuts, and damaged or out of specification timber; Milling and planing operations (including headrig, edger, resaw and planer); Wood ByProduct Chipper; Desticking, stacking, and loading for dispatch of boards; Fans in the reconditioner (tonal noise); Heat plant (boiler forced air and induced draft fans); Chipping; Reversing alarms on vehicles; and Kiln associated noises such as fans [8].

Machinery noise emission is dependent on a lot of factors as stated by D'Angelo et al., (9) in Table 1. Also, the effect on workers could be injurious if allowable noise exposure level is exceeded (Table 2). 
Table 1: Factors Affecting Machinery Noise Emissions

\begin{tabular}{|c|c|c|}
\hline Variable & Relevant Factor & Effect \\
\hline \multirow[t]{5}{*}{ Timber } & Species & $\begin{array}{l}\text { Hard, stiff timbers mean more noise and more noise } \\
\text { transmission. }\end{array}$ \\
\hline & Width & Wide work pieces radiate noise over a greater area. \\
\hline & Thickness & $\begin{array}{l}\text { Thinner work pieces generally vibrate more. Planing less } \\
\text { than } 20 \mathrm{~mm} \text { thicknesses can greatly increase the noise } \\
\text { level. }\end{array}$ \\
\hline & Length & $\begin{array}{l}\text { Long work pieces transmit noise away from the cutting } \\
\text { area towards the operator. }\end{array}$ \\
\hline & Moisture content & Dry timber is brittle and a good transmitter of noise. \\
\hline \multirow[t]{5}{*}{ Tooling } & Width of cut & $\begin{array}{l}\text { Unless helical or segmental cutters are used, the noise } \\
\text { level immediately above the cutter increases roughly in } \\
\text { proportion to the width of the cut. }\end{array}$ \\
\hline & Cutter sharpness & $\begin{array}{l}\text { Dull knives and worm blades and bands exert more force } \\
\text { on the timber and so make more noise. }\end{array}$ \\
\hline & Cutter projection & $\begin{array}{l}\text { Increases in knife projection mean that more air is } \\
\text { trapped during rotation and so more noise is produced. }\end{array}$ \\
\hline & Speed & Noise increases with tool speed. \\
\hline & Balance & $\begin{array}{l}\text { Out of balance tools means vibration and changes in } \\
\text { cutting conditions, increasing noise. }\end{array}$ \\
\hline \multirow[t]{2}{*}{$\begin{array}{l}\text { Machine } \\
\text { setting }\end{array}$} & Timber control & $\begin{array}{l}\text { The freer the timber is to vibration the greater the noise } \\
\text { level. }\end{array}$ \\
\hline & Timber support & $\begin{array}{l}\text { Noise is increased if fences, bed plates, chip breakers, } \\
\text { etc., which support the timber close to the cutting circle, } \\
\text { are not in line as close as possible to the cutting point. }\end{array}$ \\
\hline Extraction & $\begin{array}{l}\text { Air velocity/system } \\
\text { design }\end{array}$ & $\begin{array}{l}\text { Resonant conditions can lead to high noise levels. } \\
\text { Excessive turbulence and chip impact can increase noise } \\
\text { levels substantially. }\end{array}$ \\
\hline
\end{tabular}

[7, cited in 2]

Table 2: Allowable Noise Exposures Limits

\begin{tabular}{cl}
\hline Sound Level: $\mathbf{d B}(\mathbf{A})$ & Allowable exposure: hours, minutes \\
\hline 82 & 16 hours \\
83 & 12 hours, 42 minutes \\
84 & 10 hours, 5 minutes \\
85 & 8 hours \\
86 & 6 hours, 21 minutes \\
87 & 5 hours, 2 minutes \\
88 & 4 hours \\
89 & 3 hours, 10 minutes \\
90 & 2 hours, 31 minutes \\
91 & 2 hours \\
92 & 1 hour, 35 minutes \\
93 & 1 hour, 15 minutes \\
94 & 1 hour \\
95 & 49 minutes \\
96 & 38 minutes \\
97 & 30 minutes \\
\hline
\end{tabular}




\begin{tabular}{cl}
\hline 98 & 24 minutes \\
99 & 19 minutes \\
100 & 15 minutes \\
101 & 12 minutes \\
102 & 9 minutes \\
103 & 7 minutes \\
104 & 6 minutes \\
105 & 5 minutes \\
106 & 4 minutes \\
107 & 3 minutes \\
108 & 2 minutes \\
109 & 2 minutes \\
110 & 1 minute \\
\hline
\end{tabular}

Source: OSHA [10]

\section{Woodworking Machines}

The woodworking industry has experienced noise level increase as a result of modern, higher speed, and more compact machines [11]. The basic noise elements in woodworking machines are cutter heads and circular saws. Equivalent sound pressure levels (LAeq) in the furniture manufacturing industry can reach $106 \mathrm{~dB}$. Three basic noise sources associated with woodworking machinery include:

1. Structure vibration and noise radiation of the work piece or cutting tool (such as a circular saw blade) and machine frame, especially at the mechanical resonance frequencies.

2. Aerodynamic noise caused by turbulence, generated by tool rotation and the workplace in the air flow field.

3. Fan dust and chip removal air carrying systems.

Band re-saws are widely used in the wood industry. Without any measures to reduce noise at source, they can produce noise levels of over $85 \mathrm{~dB}$ (typically $100 \mathrm{~dB}$ at the operator position). At this level of noise, an employee's daily personal noise exposure would reach the $85 \mathrm{~dB}$ upper action value after 15 minutes. The Band saw noise is usually from the machine bearings, the cutting teeth, etc. When a band re-saw is idling, vibration of the blade is usually the main source of noise. When cutting, high vibration levels in the blade caused by sawdust trapped between the pulleys and blade, and vibration of the timber being sawn are the main noise sources. According to Tak et al., [12], how much the blade vibrates is affected by the: gauge of the blade; condition of the saw pulley surfaces; effectiveness of the sawdust deflection and extraction systems; effectiveness of the pulley and blade scrapers/cleaners; effectiveness of the saw blade lubrication system; adjustment of the saw guides; and blade tension.

The condition of the saw blade, and the smoothness of the pulley faces, has been found to affect idling noise levels by as much as $10 \mathrm{~dB}$. How efficient the sawdust extraction and wheel scraping/cleaning systems are, can have a similar effect. Poorly adjusted saw guides can push noise levels up by $3 \mathrm{~dB}$ and using an unnecessarily heavy-gauge sawblade produces a wider kerf (cut) can also produce more noise. A new 19 gauge $100 \mathrm{~mm}$ blade running on $900 \mathrm{~mm}$ diameter pulleys has been found to produce levels $5 \mathrm{~dB}$ higher than a new 20 gauge blade on the same machine. The three basic sources involved in the noise generated by electric motors include;

1. Broad-band aerodynamic noise generated from the end flow at the inlet/outlet of the cooling fan. The cooling fan is usually the dominant noise source.

2. Discrete frequency components caused by the blade passing frequencies of the fan.

3. Mechanical noise caused by bearing, casing vibration, motor balancing shaft misalignment, and/or motor mounting. Thus careful attention should be given to the vibration isolation, mounting and maintenance. 
Portable machine tools are also sources of noise in the wood industries and noise level varies from one machine to the other (Table 3).

Table 3: Machine Tools and Noise Level (dBA)

\begin{tabular}{|c|c|}
\hline Tool & Noise level (dBA) will probably exceed... \\
\hline Air hammer & 110 \\
\hline Belt sander & 90 \\
\hline Bulldozer (open cab) & 103 \\
\hline Chipper, pneumatic & 100 \\
\hline Chisel hammer & 102 \\
\hline Chopsaw & 92 \\
\hline Circular saw & 88 \\
\hline Compressed air gun & 104 \\
\hline Crane & 87 \\
\hline Cutoff saw & 98 \\
\hline Double scraper & 92 \\
\hline Drill & 87 \\
\hline Forklift & 93 \\
\hline Framing saw & 82 \\
\hline Grinder & 87 \\
\hline Hammer & 89 \\
\hline Jack hammer & $103-109$ \\
\hline Jigsaw & 91 \\
\hline Milling machine & 93 \\
\hline Nailgun & 97 \\
\hline Portable handheld band saw & 83 \\
\hline Reciprocating saw & 105 \\
\hline Router & 90 \\
\hline Scraper & 92 \\
\hline Table saw & 98 \\
\hline
\end{tabular}

Source: OSHA, [10]

\section{Effects of Industrial Noise Pollution}

\subsection{Health Issues}

Noise is an important factor that affects work environment. It has direct and indirect effects on workers' health and efficiency. Direct effects include hearing impairments that may lead to complete hearing loss [13], while indirect effects are backache, nervousness, annoyance, nausea, carelessness, and increased risk of accidents [14,15]. Several field of investigations for industry workers have established the strong association between high levels of exposure to noise and the risk of occupational accidents and injuries [14,16-18].

The World Health Organization (WHO) has highlighted several categories of adverse health and social effects of noise pollution, ranging from hearing impairment, interference with spoken communication, cardiovascular disturbances, mental health problems, impaired cognition, negative social behaviours and sleep disturbances [19]. The following are some of the major effects of noise on health:

\subsection{Hearing Impairment}

Noise-induced hearing loss, which occurs due to chronic exposure to high level of noise is caused by the damage of the hair cells of the cochlea in the inner ear [20]. It has been found that exposure to continuous noise of more than 85 to $90 \mathrm{~dB}$, particularly over a life time in industrial settings, can lead to hearing impairment and ultimately hearing loss [21]. Tharr, (22) in a survey in United States sawmill, revealed that $72.5 \%$ of workers exhibited some degree of hearing impairment 
at one or more audiometric test frequencies, while a study done in Cyprus among 2000 factory workers showed that after 3 years, $27.8 \%$ suffered some hearing damage while $7.7 \%$ suffered serious hearing loss [16].

\subsection{Sleep Disturbances}

Sleep disturbances is considered as the most deleterious non-auditory effect because of its impact on quality of life and daytime performance, people who have sleep problems are prone to other health problems. Experimental studies demonstrated that both sleep restriction and poor quality sleep affect glucose metabolism by reducing glucose tolerance and insulin sensitivity. Sleep restrictions has also been shown to increase blood pressure and affect immune processes [23].

\subsection{Cardio-Metabolic Disorders}

Short-term laboratory studies carried out on humans have shown that exposure to noise affects the sympathetic and endocrine systems, resulting in acute unspecific physiological responses (e.g. heart rate, blood pressure, vasoconstriction, stress hormones, electrocardiogram (ECG) changes [24]. There are evidences that implicate noise in higher incidence of diabetes, hypertension and stoke, as well mortality from coronary heart disease [23]. Many occupational studies have suggested that individuals chronically exposed to continuous noise at levels of at least $85 \mathrm{~dB}$ have higher blood pressure than those not exposed to noise [25-26]. This is also similar to findings in a study [27] that hypertension was associated with duration of exposure among continuously noise exposed workers to high levels of occupational noise (98 to $110 \mathrm{~dB}$ ).

\subsection{Concentration and Performance Impairment}

It has been noted that concentration on task and reading are affected in noisy work places, chronic exposures to noise has been implicated in problems with cognitive function and comprehension [28].

\subsection{Stress}

Noise is a psycho-social stressor that can affect physiological functioning [29]. People working in noisy environments have been noted to have higher stress levels than those exposed to less noise [30], and it appears that the longer the exposure, the greater the effects [31]

\subsection{Noise Control in the Wood Processing Industry}

Noise control is a set of strategies aimed at reducing noise pollution or impact, whether outdoors or indoors. The first step generally involves an assessment of any existing or planned noise sources and their relative contribution to ambient levels. This facilitates the establishment of target noise levels for the particular source and where necessary the degree of noise attenuation can be estimated. Having established the required reduction, the next stage is the application of noise control engineering principles. However, effective planning and management frequently involves the use of common sense and good practice as opposed to high tech engineering solutions (Figures 1 and 2) 


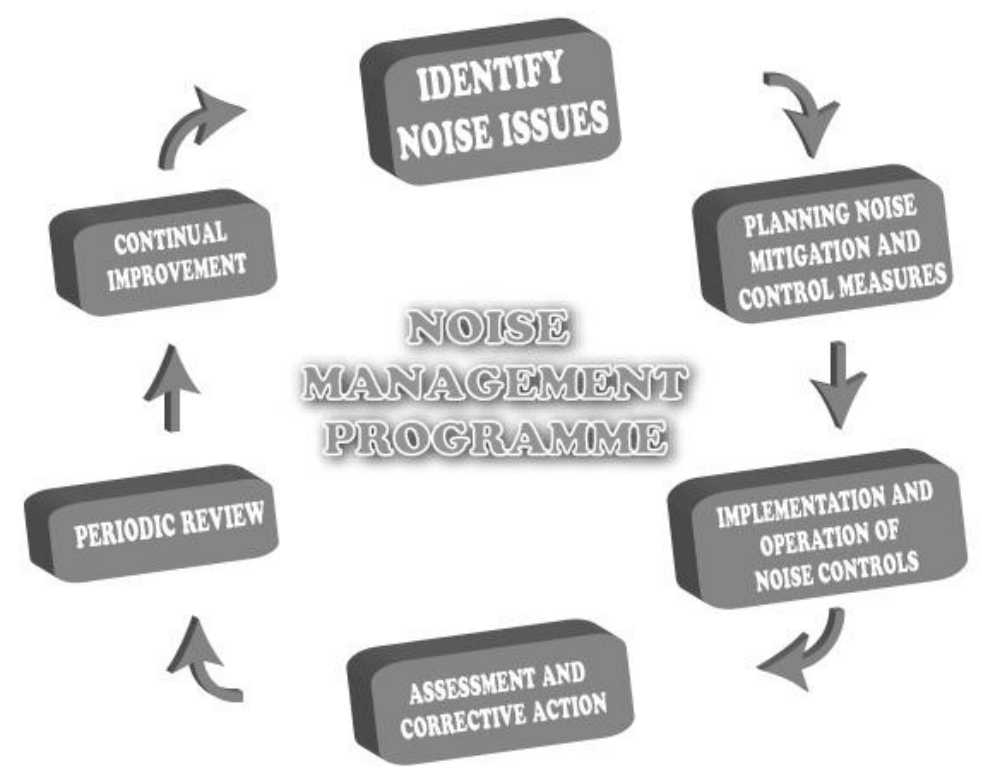

Figure 1: Noise Management Programme Source: Hearing Conservation Programme [32]

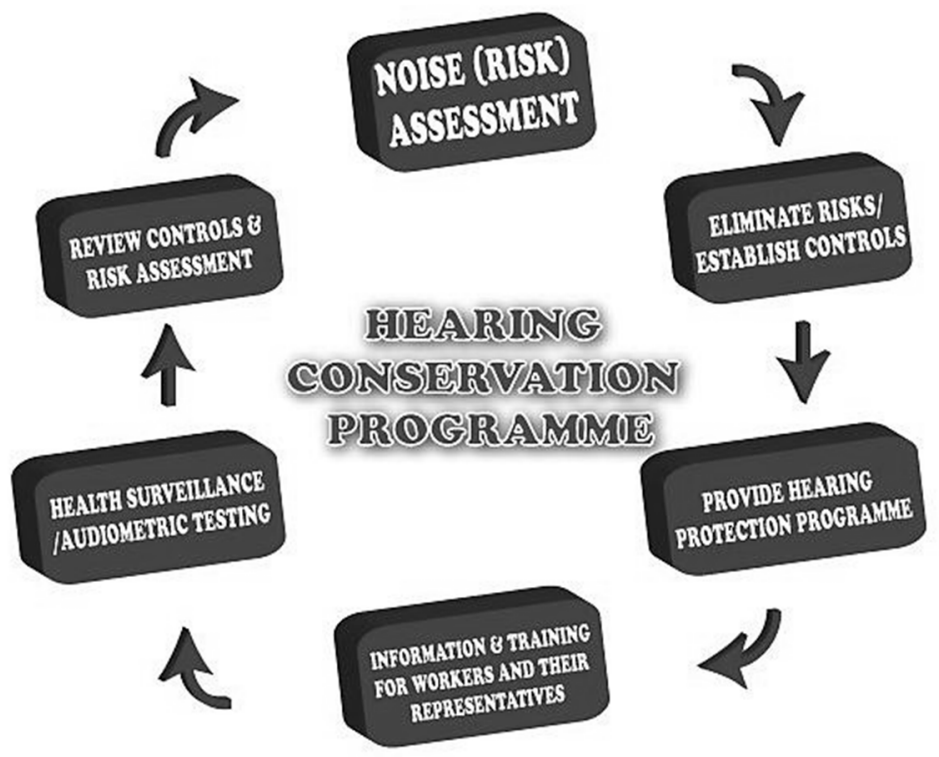

Figure 2: Hearing Conservation Programme Hearing Conservation Programme [31]

Noise control techniques according to Benz and Colin, [33] include;

1. Sound insulation: prevent the transmission of noise by the introduction of a mass barrier. Common materials have high-density properties such as brick, thick glass, concrete, metal etc.

2. Sound absorption: a porous material which acts as a 'noise sponge' by converting the sound energy into heat within the material. Common sound absorption materials include decoupled lead-based tiles, open cell foams and fiberglass 
3. Vibration damping: applicable for large vibrating surfaces. The damping mechanism works by extracting the vibration energy from the thin sheet and dissipating it as heat. A common material is sound deadened steel.

4. Vibration isolation: prevents transmission of vibration energy from a source to a receiver by introducing a flexible element or a physical break. Common vibration isolators are springs, rubber mounts, cork etc.

\subsection{Noise and Vibration Reducing Techniques}

Depending on the source, noise can be reduced in several ways according to Vaishali, et al.,

[2]; Tomozei, et al., [34]; Barron, [35]; and Beranek, et al., [36] which include;

1. Buying quiet machinery and equipment or the use a machine that emits a low noise level

2. Maintaining machinery and equipment routinely

3. Reducing machinery and equipment vibration

a. balance rotating parts to prevent imbalances

b. maintain and sharpen blades

c. use helicoidal gears instead of toothed gears in order to reduce the impacts associated with interlocking gears and the associated noise and vibration

d. install isolation dampers (springs, cork, etc.)

e. tighten parts or panels

f. use flexible connections for electrical, compressed air or hydraulic piping

g. use plastic or rubber (non-metal) materials where possible

4. Muffling engine and compressed air noise/ attaching of silencers

5. Isolating the noise source in an insulated room or enclosure

6. Placing a barrier between the noise source and the employee

7. Isolating the employee from the source in an insulated booth or room.

8. Modification of equipment and technologies

9. Decoupling technical equipment of the physical medium of work

Other ways to combat noise include;

1. Treat the room: When noise is reverberating around a room, the only way to reduce it is through absorption. Panels and baffles absorb a high percentage of sound energy and dissipate it as kinetic heat energy. Maximum noise reduction potential is from 4 to 6 decibels, resulting in a noise level reduction of 20 to 30 percent.

2. Treat the wall nearest the noise source: Another option is to cover the wall closest to the noise source with acoustic foam panels. Maximum sound reduction will vary from 2 to 6 decibels. This solution reduces noise levels from 10 to 30 percent at low cost.

3. Build a barrier or shield: Barriers can be used to create "instant walls" that isolate noisy machinery. Composite combines the sound absorption of foam and the containment of barrier material to isolate noise effectively (Fig.3). The most effective way to prevent single-source noise from reverberating around the room is to create an acoustic barrier around the machine to physically block the sound energy.

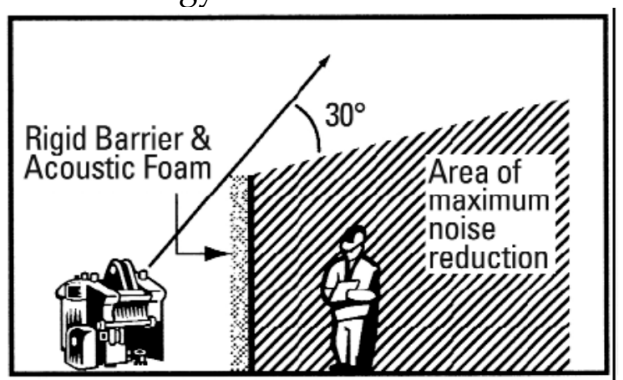

Figure 3: Build a barrier or shield

4. Build an enclosure: An acoustic enclosure around the machine also contains noise at the source. The Curtain Enclosure System provides maximum noise reduction of at least 20 to 30 
decibel. At most basic level, correction of room acoustics involves using sound-absorbing materials on three non-parallel surfaces (Fig.4). This technique suppresses unwanted reverberation by keeping sound waves from bouncing back and forth between parallel surfaces. It also reduces the overall noise level by preventing noise from building up [37].

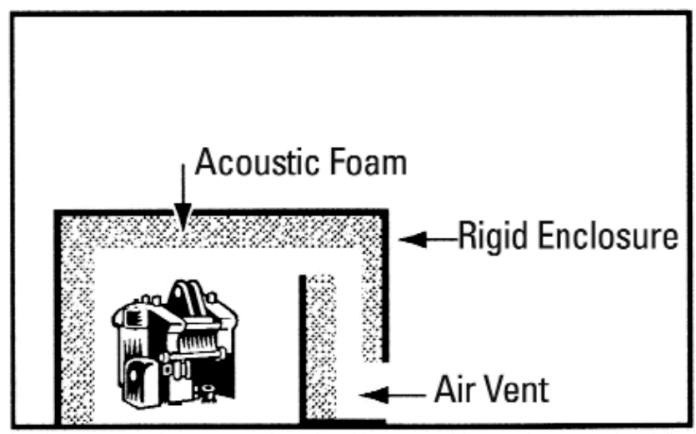

Figure 4: Build an enclosure

\subsection{Conclusion and Recommendations}

It may be concluded that industrial noise pollution can present health and social problems to the workers in the utilities industries. Concerns about reducing noise pollution in the industry are multiple and directed to problems aimed the noise in the three directions: at source, on the propagation paths and at receiver. Noise control methods are effective when all the factors related to the nature of noise, the device which produces noise, the propagation pathways and the environment in which it propagates are studied. In order to reduce the noise, acoustic barriers, overhang baffles and acoustic foam on the side walls may be installed. And in order to reduce the noise at the source i.e. at the machine dampers may be used between the machine and the foundation block to reduce the vibration. Acoustic enclose may be installed either partially or fully to reduce noise. Another safety measure that should be taken at source is the use of earplugs by the operator, as he is the person who is exposed to this more.

Based on the review, the following recommendations are proffered

1. The first step consists of identifying and quantifying the noise exposure experienced by employees. It should be obvious that the risk of hearing loss will not only depend on the noise levels themselves but also on their duration. Therefore it is essential to assess the total amount of noise to which the individual workers are exposed, i.e, the Noise Dose.

2. If the noise dose is greater than $100 \%$, depending on the referred standard, noise control / reduction measures should be applied. It may be possible to reduce the noise; however, it may not be feasible to do so in practice due to the inordinate cost involved.

3. The most important step in noise control is to use the first line of defense against hazardous industrial noise exposure that is the application of engineering control, such as replacing or modifying noisy machines, better installation and maintenance of machines, and where necessary, enclosing and / or isolating of every noise sources, etc.

4. The fourth step consists of making a scaled map of the particular factory or enterprise site showing all the noise resources. On this map lines can then be traced connecting points of equal noise levels.

5. In situations where it is no longer possible to reduce the noise, it is necessary to ensure the protection of the people whose noise dosage was found to be above $100 \%$. This may be done, for example, by prescribing wearing of earplugs or ear muffles or rotation of personnel working at the most noisy posts with personnel in quieter areas.

6. Even at this point not all noise problems are entirely solved. The limit corresponding to a dosage of $100 \%$ will protect most of the workers, but not necessarily all. The means of protecting the individuals may not be perfect or are not used properly. The only way to obtain a guarantee of the success of any industrial hearing conservation program is to test the hearing ability of the employees periodically. 


\section{REFERENCES}

1. Environmental Protection Authority-EPA. Wood Processing Works. Environmental Protection Authority. Available online: http://www.epa.sa.gov.au/xstd_files/Industry/Guideline/ea_wood .pdf. Accessed on the 23rd of May 2013

2. Vaishali, P. C.; Deepak, S.D.; Chandrakant R.P. Assessment and Control of Sawmill Noise. International Conference on Chemical, Biological and Environment Sciences (ICCEBS'2011) Bangkok Dec., 2011. 299-303pp

3. Samir N.Y.G.; Gustav, A.S.; Wolfgang, P. Noise Sources. Available online: http://www.who.int/ occupational_health/publications/noise5.pdf. Accessed on the 26th of June 2016

4. Bugliarello, G.; Alexandre, A.; Barnes, J.; Wakstein, C. The Impact of Noise Pollution: A SocioTechnological Introduction. New York: Pergamon Press. 1976

5. Atkins, W.S. Noise and Vibration, England "RoadNoise 2000" computer software, 2000. 1997

6. Miyerkules, P. Definition of Noise Pollution. Noise Pollution. Available online: http://mynewbl oggerspt.blogspot.com.ng/2016/02/noise-pollution-disturbance-disturbing.html

Accessed on the 26th of June 2016

7. Pinte, G.; Boonen, R.; Desmet, W.; Sas, P. Active structural acoustic control of repetitive impact noise, Journal of Sound and Vibration, vol. 319, no. 3-5, 2009: p.768-794.

8. Southwood Resources. Chapter 7. Regrowth Sawmill. The Wood Centre Development, Southwood Resources - Huon Development Proposal and Environmental Management Plan Forestry Tasmania. Available online: http://www.southwoodresources.com.au/southwood/pdf/ planning/DPEMP7.pdf. Accessed on the 26th of June 2016

9. D'Angelo C.; Alvarado, N.T.; Wang, K.W.; Mote, C.D. Current Research on Circular Saw and Band Saw Vibration and Stability. Shock and Vibration Digest, Vol.17, No. 5, May 1985.

10. OSHA: Occupational Safety \& Health Administration (OSHA) Noise Regulations. Construction Safety Association of Ontario and the American Society of Safety Engineers (ASSE) standard, ANSI/ASSE A10.46-2007 - Hearing Loss Prevention in Construction and Demolition Workers. www.osha.gov/SLTC/noisehearingconservation/standards.html. 2013

11. Samir, N.Y.; Gerges, G.A.; Wolfgang, P. Noise Sources. Available on: www.who.int/occupational_ health/publications/noise5.pdf. Accessed on the 23 $3^{\text {rd }}$ of May, 2013

12. Tak, S.; R.R. Davis; and G.M. Calvert. Exposure to Hazardous Workplace Noise and Use of Hearing Protection Devices Among US Workers - NHANES, 1999-2004. American Journal Of Industrial Medicine. 52(5): 2009; p. 358.

13. Parsons, K.C. Environmental ergonomics: a review of principles, methods, and models. Applied Ergonomics, 31: 2000. 581-594.

14. Ali, S.A. Industrial noise levels and annoyance in Egypt. Applied Acoustics, 72: 2011: 221-225.

15. Ekerbicer, H.; Saltik, A. The health consequences of industrial noise and methods for protection. TAF Preventive Medicine Bulletin, 7(3): 2008. 261-264.

16. Eleftherou, P.C. Industrial noise and its effect on human hearing. ibid., 63: 2002. 35-42.

17. Picar, M.; Girard, S.A.; Simard, M.; Larocque, R.; Leroux, T.; Turcotte, F. Association of workrelated accidents with noise exposure in the workplace and noise-induced hearing loss based on the experience of some 240,000 person-year of observation. Accident Analysis and Prevention, 40: 2008: 1644-1652.

18. Palmer, K.T.; Harris, E.C.; Coggon, D. Chronic health problems and risk of accidental injury in the workplace: a systematic literature review. Occupational Environmental Medicine, 65(11): 2008: 757-64.

19. Demain, H. Environmental Noise and Sleep Disturbances: A Threat to Health: Sleep Science. 7: 2014: 209-212

20. Olaosun, A.O.; Ogundiran, O.; Tobih, J.E. Health Harzards of Noise: A Review Article Research Journal of Medical Sciences 3(3). 2009: 115-122

21. Kryter, K.D. The handbook of hearing and the effects of noise: physiology, psychology, and public health. Boston: Academic Press. 1994: 688p. 
22. Tharr, D. A sawmill environment: Noise levels, controls and audiometric test results. Appl Occup Environ Hyg 6(12):1999: p1000.

23. Adejobi, O.S. Spatio-temporal analysis of noise pollution levels in Lagos State. Oshodi-Agege Route Experience. European Journal of Globalization and Development. Vol. 5 No.1 2012: pp266-284

24. Babisch, W. Cardiovascular Effects of Noise: Noise and Health Journal 13 (52). 2011: 201-204

25. Zhao, Y.; Zhang, S.; Selin, S.; Spear, R.C.A. A Dose Response Relation for Noise Induced Hypertension. Br. J. Ind Med; 1991179-184

26. Lang, T.; Fouriaud, C.; Jacquinet, M.C. Length of Occupational Noise Exposure and Blood Pressure. Int. Arch Occup Environ Health: 63: 1992: 369-372

27. Uday, W.; Narlawar, W.; Surjuse, B.G.; Thakre, S.S. Hypertension and Hearing Impairment in workers of iron and steel industry. Indian J. Physiol Pharmacol; 50:2006: 60-66

28. Awosusi, A.O.; Akindutire, I.O. Perceived Health Effects of Environmental Noise Pollution On the Inhabitants of Ado-Ekiti Metropolis. Ekiti State, Nigeria. Journal of Biology, Agriculture and Healthcare. 4(26): 2014. Pp106-133

29. Babisch, W. Stress Hormones in the Research on Cardiovascular Effects of Noise, Noise and Health Journal 5(18). 2002: p1-11

30. Scott G.R.; Johnson I.A. Temperature during embryonic development has persistent effects on thermal acclimation capacity in zebrafish. Proceedings of the National Academy of Sciences of the United States of America, 109, 2012: 14247-14252

31. Spiegel K.; Leproult R.; Van Cauter E. Impact of sleep debt on metabolic and endocrine function. Lancet. 354:1999: 1435-1439.

32. HCP. Noise Control \& Vibration Assessment Services. Hearing Conservation Programme (HCP) for the control and management of workplace noise: Available oneline: www.acousticenvironmental.ie/noise_vibration.php. Accessed on the 23 $3^{\text {rd }}$ of May 2013

33. Benz Kotzen; Colin English. Environmental Noise Barriers: A Guide to Their Visual and Acoustic Design, Spon Press, United Kingdom (1999) ISBN 978-0-419-23180-6

34. Tomozei, C.; Nedeff, V.; Lazar G. Actual Stage of Industrial Noise Reduction. Journal of Engineering Studies and Research - Volume 17 (2011) No. 4: pp89-95

35. Barron, R.F. Industrial Noise Control and Acoustics, edited by Marcel Dekker, New York. 2003

36. Beranek, L.L.; Ver Istvan, L. Noise and Vibration Control Engineering, Edited by, John Wiley \& Sons Inc, 1992.

37. Fredel, S.C. Industrial Jet Noise", (in Portuguese). M.Sc. dissertation at the Federal University of Santa. 1999

(C) 2016 by the authors; licensee Preprints, Basel, Switzerland. This article is an open access article distributed under the terms and conditions of the Creative Commons by Attribution (CC-BY) license (http://creativecommons.org/licenses/by/4.0/). 